\title{
Human-Wildlife Conflict around Belo-Bira Forest, Dawro Zone, Southwestern Ethiopia
}

\author{
Getahun Shanko $\mathbb{D}^{D}$, Bekele Tona ${ }^{D}$, and Barena Adare \\ Department of Natural Resource Management, Wolaita Sodo University, Dawro Tarcha Campus, P.O. Box 01, Tarcha, Ethiopia \\ Correspondence should be addressed to Getahun Shanko; getuwetm@gmail.com
}

Received 3 March 2021; Revised 24 June 2021; Accepted 9 July 2021; Published 20 July 2021

Academic Editor: Daniel I. Rubenstein

Copyright (c) 2021 Getahun Shanko et al. This is an open access article distributed under the Creative Commons Attribution License, which permits unrestricted use, distribution, and reproduction in any medium, provided the original work is properly cited.

\begin{abstract}
Human-wildlife conflict (HWC) is a continuous problem in the world and has a significant impact on both human and wildlife populations. This study was conducted to investigate the HWC around Belo-Bira Forest, Dawro zone, southwestern Ethiopia. We collected data from October 2019 to March 2020 through semistructured questionnaires, focus group discussion, direct observation, and key informant interviews. Our results show that crop damage and livestock predation were common problems caused by Papio anubis, Cercopithecus aethiops, Crocuta crocuta, Canis aureus, and Potamochoerus larvatus. Human population growth, habitat disturbance, proximity to natural forest, and competition between wildlife and livestock are the identified causes of HWC. Moreover, the study identified guarding and fencing as dominant traditional methods used to reduce HWC in our study area. Therefore, local communities can minimize crop loss by using the most effective method in an area, and crops such as wheat, maize, and teff should not be grown near the forest edge.
\end{abstract}

\section{Introduction}

Human-wildlife conflict (HWC) is regarded as any interaction between humans and wildlife that results in negative impacts on humans, animals, or the environment. The impacts on humans could have social, economic, or cultural forms, while the impact on wildlife can range from decreasing numbers to local extinctions. Conflicts between people and wildlife have been widely recognized as one of the most challenging problems for wildlife conservation worldwide [1].

HWC is common where wildlife and human populations coexist and share limited resources and has become a considerable problem throughout the world [2]. The continuous increase in human population results in competition between people and wildlife for shared but limited resources, which manifests as various types of conflict, such as crop raiding, livestock depredation, property damage, human injury and death, and the retaliatory killing of wildlife.

HWCs have been in existence as long as wildlife and people shared resources. Sharing and competition for limited resources will lead to HWC. Crop raiding by wild animals is a common problem all over the world. This conflict is worsening in areas where people and wildlife overlap [3], and it has been recorded to occur everywhere in the world. People living in developing countries of Africa and Asia are suffering from the negative impact of humanwildlife conflict, such as crop damage and livestock predation [4].

Local communities grazing the protected area by entering areas traditionally inhabited by wild animals is the main problem for HWC. Though, large numbers of the local community live within the protected area and the local community encroaches onto the protected area and the native wildlife and humans are brought into conflict in the Yabello Protected area [5]. The local communities in different parts of the protected area use the forest products to support their daily consumption and marketing goods such as charcoal is another factor.

Ethiopia has a large number of wildlife species with diverse ecology and unique environmental conditions [6]. However, wildlife habitats have been degraded, fragmented, and lost in most parts of the country, and the wildlife species are largely restricted over a few protected areas [7]. Almost 
all protected areas in Ethiopia are surrounded by agricultural landscape, whereby there is an immediate contact between the wildlife species and the people [7]. This in turn escalates HWCs. Thus, HWCs negatively affect marginal communities through the loss of access to livelihood resources such as crops and domestic animals and may lead to an increased negative impact on wildlife due to retaliatory killing by the people.

Human-wildlife conflicts have been more intensive in recent decades, because of exponential human population growth and economic activities. The highest intensity of conflicts tends to occur when humans live adjacent to protected across the country [8]. So far, no attempt has been made to assess the magnitude of the wildlife conflict with local communities living adjacent to the Belo-Bira forest. Therefore, the objective of this study was to determine the causes, impacts, and management options of HWCs in and around Belo-Bira forest, Dawro zone, southwestern Ethiopia.

\section{Materials and Methods}

2.1. Description of Study Area. Belo-Bira forest is located in southwestern Ethiopia, in Essera district, Dawro zone, Southern Nations and Nationalities Peoples Region (SNNPR). It is located at $7^{\circ} 14^{\prime} \mathrm{N}$ latitude and $37^{\circ} 5^{\prime} \mathrm{E}$ longitude (Figure 1). Essera district is a richly forested area surrounded by Konta special district, Tocha district, Loma district, Mareka district, and Omo River.

The forest comprising a total of 62 woody species belonging to 50 genera and 31 families were identified. Among the families, Moraceae is the most abundant with seven species followed by Fabaceae with 6 species, Myrtaceae with 5 species and Ficus was the most widely abundant genus. The annual mean temperature ranges between 15.1 and $27.5^{\circ} \mathrm{C}$, and the average annual rainfall ranges from 1201 to $1800 \mathrm{~mm}$. It has a bimodal rainfall, with the short rainy season from February to March and the long from May to September [9].

2.2. Study Design and Site Selection. Before the data collection, we conducted a reconnaissance survey to identify the number of kebeles (neighborhoods) near the forest and to start discussions with local residents and conservation agents regarding our research questions. In addition, the questionnaire was tested among randomly selected individuals who are not included in the data collection. The main purpose of the testing was to evaluate the questionnaire and to check whether it is applicable and suitable in the study area and based on the result, the questionnaire was revised and developed. We selected four kebeles (Bale, Arusi Bale, Zadi Shamayit, and Zadi Woyid), on the basis of their proximity to the forest, for the data collection. The description of the sample selected is described in Table 1.

2.3. Methods of Data Collection. We collected data from October 2019 to March 2020. We used a standard questionnaire to collect primary data from respondents living around the forest. The first section of the questionnaire asked about demographic information (e.g., gender, education status, family size). The second section asked about the socioeconomic and environmental aspects (e.g., the type and number of livestock they own, the size of their land, and how far away their grazing land is from the forest). The third section asked about the ecological and environmental aspects (which wildlife exists in the area, human-livestockwildlife interactions, resource use, and tenure patterns).

In order to strengthen the information collected through the questionnaire, eleven key informants (three experts from Woreda, one development agent from each kebele, and four local elders) were also interviewed. Semistructured questionnaires (covering the cause, consequences, type, topranked damage-causing wild animals, and traditional methods practiced by farmers to prevent damages) were developed and asked to gain relevant information.

We also carried out a focused group discussion to collect qualitative information from the selected four kebeles one per each. The group size in each discussion varied from 9 to 13 people and discussions were made under the guidance of a moderator.

In addition, field observation was also used to confirm the respondent's responses, so that accurate and reliable information would be collected during field observation. The observation was carried out in four selected kebeles to obtain data on distance between the park and farmlands, nature of wild animals, and frequency of the coming crop raiding wild animals to farmlands. We determined the total number of households that were sampled in each kebele using the formula in Yamane [10].

The populations in Bale, Arusi Bale, Zadi Shamayit, and Zadi Woyid were 2084, 1641, 1307, and 1282, respectively [9]. Using the formula, we calculated a sample size of 152 households from the total population of 6314 . We proportionally distributed the number of households sampled in each kebele. Accordingly, 50, 39, 32, and 31 sample households were randomly selected from Bale, Arusi Bale, Zadi Shamayit, and Zadi Woyid, respectively.

2.4. Data Analysis. Data collected was analyzed statistically using Statistical Package for the Social Sciences (SPSS ver. 20). Descriptive statistics and Pearson chi-square test were used for the analysis of the collected data. Pearson chi-square test was used to determine the significant difference of villages in ways of protecting crop damage, trends in crop damage, local people's attitude towards wildlife, and types of conflict they faced by wild animals. The Chi-square test at $P<0.05$

(2-tailed) was considered significant. The information was collected from group discussion summarized by text analysis and presented in a narrative way.

\section{Results and Discussion}

3.1. Demographic Characteristics of Respondents. Out of 152 household questionnaires administered, a total of 151 responses were received and suitable for analysis. The results of 


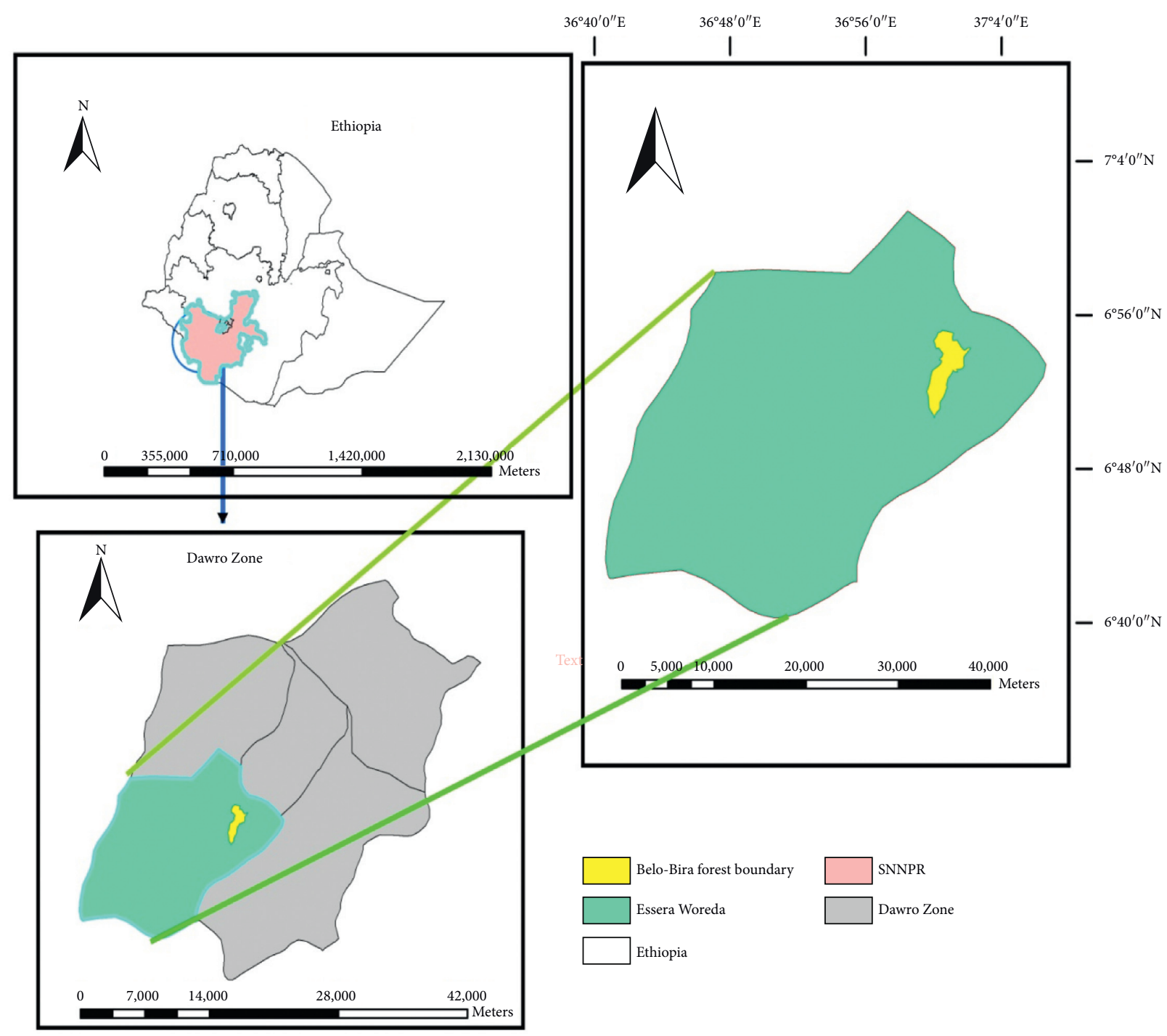

FIgURE 1: Locations of Belo-Bira forest.

TABle 1: Demographic characteristics of sampled population.

\begin{tabular}{|c|c|c|c|}
\hline \multicolumn{2}{|c|}{ Demographic characteristics } & \multirow{2}{*}{$\begin{array}{c}\text { Frequency } \\
97\end{array}$} & \multirow{2}{*}{$\begin{array}{c}\text { Percent } \\
64.2\end{array}$} \\
\hline Sex & Male & & \\
\hline $\operatorname{sex}$ & Female & 54 & 35.8 \\
\hline \multirow{3}{*}{ Age } & Adult $18-35$ & 76 & 50.3 \\
\hline & Middle (36-45) & 49 & 32.5 \\
\hline & Elder $(>46)$ & 26 & 17.2 \\
\hline \multirow{4}{*}{ Educational status } & Uneducated & 38 & 25.2 \\
\hline & Elementary & 28 & 18.5 \\
\hline & Secondary school & 44 & 29.1 \\
\hline & High school and above & 41 & 27.2 \\
\hline \multirow{4}{*}{ Household economy } & Agriculture & 37 & 24.5 \\
\hline & Small scale merchants & 28 & 18.5 \\
\hline & Governmental work & 25 & 16.6 \\
\hline & Mixed (agriculture and trade) & 61 & 40.4 \\
\hline \multirow{4}{*}{ Farmland size } & Less than 1 hectare & 36 & 23.8 \\
\hline & 1-2 hectares & 49 & 32.5 \\
\hline & $2-3$ hectares & 38 & 25.2 \\
\hline & Greater than 3 hectares & 28 & 18.5 \\
\hline
\end{tabular}


demographic characteristics showed that 97 (64.2\%) were males and 54 (35.8\%) were females (Table 1).

Among the overall sample of 151 , about $64.2 \%(n=97)$ of them were male and the rest $35.8 \%(n=54)$ were female. The majority of the respondents $125(82.8 \%)$ were between 18 and 45 years. Statistically, there is a significant difference in $\operatorname{sex}(\chi 2=24.887, \mathrm{~d} f=2 P \leq 0.001)$.

The size of farmlands owned by sampled household $(\mathrm{HH})$ ranged from 0.5 to 4 ha with an overall mean of 2.38 ha. There was no significant difference among $\mathrm{HH}$ heads in sizes of farmland $(\chi 2=5.9536, \mathrm{~d} f=3, P<0.05(0.114))$.

3.2. Human-Wildlife Conflict. Of the total respondents interviewed, about $72.2 \%$ reported that there was both the problem of crop damage and livestock predation by wild animals (Table 2). Both kinds of damage caused by wildlife were associated with interactions between humans and wildlife.

The responses of respondents from each kebele were significantly different regarding different types of conflict, namely, crop raiding, livestock predation, and both caused by wild animals in the study area $\left(\chi^{2}=1.788, \mathrm{~d} f=6\right.$, $P \leq 0.001)$.

The occurrence and frequency of HWC were dependent on various conditions such as the activity of humans on a farm, the availability of food sources, the type of crop grown, and ripened time. The result was in agreement with different studies in Ethiopia (Amaja et al. [11], Yirga and Bauer [12], and Teklay and Zeyede [13]) which reported the cause of HWC was both crop damage and livestock predation.

Damaged crops include wheat, maize, bean, teff, pea, coffee, enset, barley, and sorghum while the depredated livestock were cattle, sheep, and goats. About $54.3 \%$ of respondents responded with coffee, wheat, bean, and pea as the top four crops widely affected in all sampled kebeles. According to Datiko and Bekele [14], particular food like maize, teff, and sorghum attract crop raiders around Chebera Churchura National Park in Ethiopia.

The present study reveals that about two carnivores, one omnivore, two primates, and others such as Histrix cristata were wild animals interacting negatively with the surrounding communities (Table 3). Anubis baboon (Papio anubis) was the most commonly known primate species followed by Vervet monkeys (Cercopithecus aethiops). Likewise, a survey conducted in Senkele Swayne's Hartebeest Sanctuary showed livestock loss by wild carnivores [15]. The majority of our respondents attributed this to the uncontrolled population growth of Papio anubis. The other caustic animals include spotted hyaena (Crocuta crocuta), common jackal (Canis aureus), and Bush pig (Potamochoerus larvatus). Those wild animals cause both crop damage and livestock predation. Among different predators, common jackal and spotted hyaena were considered as more problematic to the community they live in and around the Semien Mountains National Park SMNP than others [16]. Muluken [17] also reported that, in Ethiopia, wildlife such as bush pigs, baboons, giant forest hogs, warthogs, common monkey, and porcupine were common agricultural pests in villages close to forest areas.
The trend of HWC among approximate distance from the forest differed significantly $\left(\chi^{2}=31.125, \mathrm{~d} f=4\right.$, $P \leq 0.001)$.

Respondents that live close/near to the forest faced higher HWC than those far from the forest (Table 4). This result is in line with the study of Datiko and Bekele [14] and Merkebu and Yazezew [18] who reported that those communities who live near the park faced frequent crop damage.

3.3. Causes of Human-Wildlife Conflict. The household survey respondents prioritized the increase in human population, habitat encroachment, proximity to natural forest, and competition between wildlife and livestock as the major causes of HWC.

Bale reported the $46 \%$ human population growth as the cause for HWC. On the other hand, none from Zadi Shamayit reported human population growth as the cause for HWC (Table 5). There was a significant difference $(\chi 2=41.537, \mathrm{~d} f=12, P \leq 0.001)$ among villages in terms of causes of HWC. In line with Yirga and Bauer [12], human population growth and the associated increase in rates of natural resource use, habitat modification, and fragmentation are forcing wild animals to live close to human settlements. Similarly, the establishment of conservation areas in close proximity to human livelihood activities has also resulted in human-wildlife conflicts [19]. Amaja et al. [11] also reported that the highest cause of HWC was disturbances of habitat followed by proximity to natural forest and increased subsistence agriculture.

\subsection{Measures by Local Communities for Prevention of HWC.} In the study area, households used different mechanisms to protect their crop and livestock from damage by wild animals. As reported by respondents across all kebeles, different methods are used by local communities to reduce HWC for both crop damage and livestock predation.

These include guarding (88\%), fencing (71\%), scarecrow (66\%), and chasing (32\%) as shown in Figure 2. This result agrees with the finding of Johansson [20] who found that guarding and live fences to keep animals away were ranked first and second in protecting crop raiders from crops. Even though it is time-consuming, guarding is the most effective strategy of the local communities used in preventing HWC, specially crop damage [21].

\subsection{Perception of Local Communities toward Wildlife.} Focus group discussions revealed that local residents generally held positive attitudes towards wildlife and the forest itself. Reasons given for the importance of wildlife across the forest areas included its attraction as a future tourist destination and its value for future generations. However, levels of support differed across the four study sites, with the lowest level of support (60\%) expressed by respondents from Zadi Shamayiti. The result showed that the probability that a community wished to protect wildlife was related to whether they had previously received 
TABLE 2: Percentage of types of conflict by wild animals in each kebele.

\begin{tabular}{lcccc}
\hline Kebeles & No. & Crop damage only & Livestock predation only & Both crop damage and livestock predation \\
\hline Bale & 50 & $10(20 \%)$ & $6(12 \%)$ & $34(68 \%)$ \\
Arusi Bale & 39 & $5(12.8 \%)$ & $6(15.4 \%)$ & $28(71.8 \%)$ \\
Zadi Shamayit & 32 & $5(15.6 \%)$ & $3(9.4 \%)$ & $24(75 \%)$ \\
Zadi Woyid & 30 & $4(13.3 \%)$ & $3(10 \%)$ & $23(76.7 \%)$ \\
\hline
\end{tabular}

TABLE 3: Response rate on animals that cause HWC in the study area.

\begin{tabular}{|c|c|c|c|c|c|}
\hline \multirow{2}{*}{ Animals that cause HWC } & \multicolumn{5}{|c|}{ Kebele } \\
\hline & Bale & Arusi Bale & Zadi Shamayit & Zadi Woyid & Total \\
\hline Papio anubis & 16 & 11 & 18 & 9 & 54 \\
\hline Cercopithecus aethiops & 11 & 8 & 0 & 3 & 22 \\
\hline Crocuta crocuta & 8 & 0 & 5 & 6 & 19 \\
\hline Potamochoerus larvatus & 9 & 5 & 4 & 5 & 23 \\
\hline Canis aureus & 4 & 15 & 4 & 7 & 30 \\
\hline Other & 2 & 0 & 1 & 0 & 3 \\
\hline Total & 50 & 39 & 32 & 30 & 151 \\
\hline
\end{tabular}

TABLE 4: Response rate on approximate distance from the forest and trends of HWC in the last three years.

\begin{tabular}{lcccc}
\hline Distance from forest & \multicolumn{2}{c}{ Trends of HWC } & Low & Total \\
\hline Near & High & Medium & 20 & 59 \\
Medium & 39 & 22 & 11 & 14 \\
Far & 22 & 15 & 55 \\
Total & 8 & 57 & 37 \\
\hline
\end{tabular}

TABLE 5: Response rate on the major causes of HWC in the study area.

\begin{tabular}{|c|c|c|c|c|c|}
\hline \multirow{2}{*}{ Cause of HWC } & \multicolumn{5}{|c|}{ Kebele } \\
\hline & Bale & Arusi Bale & Zadi Shamayit & Zadi Woyid & Total \\
\hline Human population growth & 23 & 10 & 0 & 11 & 44 \\
\hline Habitat encroachment & 14 & 9 & 11 & 8 & 42 \\
\hline Village proximity to forest & 9 & 8 & 18 & 5 & 40 \\
\hline Competition between wildlife and livestock & 4 & 11 & 3 & 4 & 22 \\
\hline Other & 0 & 1 & 0 & 2 & 3 \\
\hline Total & 50 & 39 & 32 & 30 & 151 \\
\hline
\end{tabular}

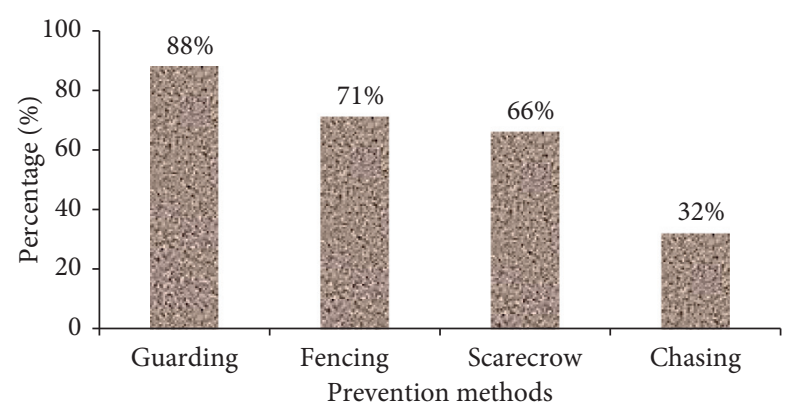

FIgUre 2: Measures to reduce HWC in the study area.

benefits from the forest, the numbers of livestock they owned, the frequency of wild animal predation, and whether they had visited the protected area.

Overall, three-quarters of respondents felt that wildlife and people could coexist. Local views on coexistence varied across the four study sites, however, with the least support
(16\%) expressed by respondents from Bale. The result indicated that the probability of a community expressing the belief that wildlife and people can coexist was related to income source and whether or not the respondent had received benefits from the nearby protected area. The result agrees with Acha and Temesgen [22], Teklay and Zeyede 
[13], Yirga and Bauer [12], Dawit et al. [23], and Tessema et al. [24] that local communities have a positive attitude towards wildlife in their surroundings.

Some limitations of this research were that the total amount of crop damaged and number of livestock depredated were not measured. Additionally, an appropriate assessment of wild animals' resources in the forest area should be conducted to decide the carrying capacity of the forest to uphold wild animals.

\section{Conclusion}

According to the current result, HWC can have adverse impacts on wildlife and humans alike. It indicates that crop damage and livestock predation were the common problems for the conflict between humans and wildlife in the study area. Papio anubis, Cercopithecus aethiops, Crocuta crocuta, Canis aureus, and Potamochoerus larvatus were common wild animals that cause HWC. The increase in human population, habitat disturbance, proximity to natural forest, and competition between wild animals and livestock were the major causes of HWC, as described by respondents. Guarding, fencing, scarecrow, and chasing are some of the techniques used to reduce HWC in the study area. Therefore, we recommend that local communities should keep their farm against crop raiders to minimize crop loss by using the most effective method in an area, and crops such as wheat, maize, and teff should not be grown near the forest edge.

\section{Data Availability}

The data used are available from the corresponding author upon request.

\section{Conflicts of Interest}

The authors declare that there are no conflicts of interest.

\section{Acknowledgments}

The authors would like to offer their sincere thanks to Essera Woreda Natural Resource Management Office's staff members and local communities for giving them an opportunity to pursue this research.

\section{References}

[1] IUCN, Preventing and Mitigating Human-Wildife Conflicts WPC Recommendation V.20, International Union for Conservation of Nature, Gland, Switzerland, 2010.

[2] K. Schwerdtner and B. Gruber, "A conceptual framework for damage compensation schemes," Biological Conservation, vol. 134, no. 3, pp. 354-360, 2007.

[3] E. Gandiwa, L. M. A. Heitkönig, A. M. Lokhorst, H. H. T. Prins, and C. Leeuwis, "CAMPFIRE and humanwildlife conflicts in local communities bordering Northern Gonarezhou National Park, Zimbabwe," Ecology and Society, vol. 18, no. 4, pp. 4-17, 2013.

[4] K. Taylor, "Vertebrate pest problems in Africa," in Proceeding of a Conference on the Organization and Practice of Vertebrate Pest Control, pp. 21-28, Hampshire, UK, August1982.
[5] F. Tesfaye and D. Jatni, "Human-wildlife conflict among the pastoral communities of southern rangelands of Ethiopia: the case of Yabello protected area," Journal of International Wildlife Law \& Policy, vol. 20, no. 2, pp. 198-206, 2017.

[6] D. W. Yalden and M. J. Largen, "The endemic mammals of Ethiopia," Mammal Review, vol. 22, no. 3, pp. 115-139, 1992.

[7] T. Kumssa and A. Bekele, "Human-wildlife conflict and population status of Swayne's hartebeest (alcelaphusbuselaphusswaynei) in Senkele Swayne's hartebeest sanctuary," Master thesis in Biology (Ecological and Systematic Zoology), Addis Ababa University, Addis Ababa, Ethiopia, 2008.

[8] A. Hammill and C. Besancon, "Promoting conflict sensitivity in Trans-boundary protected areas: a role for peace and conflict impact assessments," in Proceedings of Transboundary Protected Areas in the Governance Stream of the 5th World Parks Congress, pp. 56-61, Durban, South Africa, September 2003.

[9] Essera District Agriculture and Natural Resource Management Office, Socio-Economic and Geo-Spatial Data Analysis and Dissemination Core Work Process, Essera District Agriculture and Natural Resource Management Office, Dawuro Zone, Ethiopia2020, Annual Report.

[10] T. Yamane, Statistics, an Introductory Analysis, Harper \& Row, Manhattan, NY, USA, 2nd edition, 1967.

[11] L. G. Amaja, D. H. Feyssa, and T. M. Gutema, "Assessment of types of damage and causes of human-wildlife conflict in Gera district, South Western Ethiopia," Journal of Ecology and the Natural Environment, vol. 8, no. 5, pp. 49-54, 2016.

[12] G. Yirga and H. Bauer, "Prey of periurban spotted hyena (Crocuta crocuta) in Southeastern Tigray, Northern Ethiopia," Asian Journal of Agricultural Sciences, vol. 2, no. 4, pp. 124127, 2010.

[13] G. Teklay and T. Zeyede, "Human-wildlife conflicts in and around choffa forest, hawzien woreda, eastern tigray, Northern Ethiopia: Implication for conservation and conflict resolution," International Journal of Science and Research (IJSR), vol. 6, no. 1, pp. 1763-1771, 2017.

[14] D. Datiko and A. Bekele, "Conservation challenge: humanherbivore conflict in Chebera Churchura National Park, Ethiopia," Pakistan Journal of Biological Sciences, vol. 16, no. 23, pp. 1758-1764, 2013a.

[15] T. Kumssa and A. Bekele, "Human-wildlife conflict in Senkele Swayne's Hartebeest Sanctuary, Ethiopia," Journal of Experimental Biology and Agricultural Sciences, vol. 1, no. 1, pp. 33-38, 2013.

[16] M. Yihune, A. Bekele, and Z. Tefera, "Human-wildlife conflict in and around the Simien Mountains national park, Ethiopia," SINET: Ethiopian Journal of Science, vol. 32, no. 1, pp. 57-64, 2009.

[17] M. Muluken, "Human-wildlife conflicts: Case study in wondo genet district, southern Ethiopia," Agriculture, Forestry and Fisheries, vol. 3, no. 5, pp. 352-362, 2014.

[18] S. Merkebu and D. Yazezew, "Assessment of human-wildlife conflict and the attitude of local communities to wild animal conservation around Borena Sayint National Park, Ethiopia," International Journal of Ecology, vol. 2021, Article ID 6619757, 8 pages, 2021.

[19] T. Haylegebriel, "Human-wildlife interaction: wildlife crop raiding conflict in Ethiopia," International Journal of Science and Research (IJSR), vol. 6, no. 391, pp. 1188-1191, 2015.

[20] T. Johansson, The Spatial Dimension of Human-Wildlife Conflicts, Discoveries of New Animal Geography, University of Helsinki, Helsinki, Finland, 2002. 
[21] E. A. Eniang, H. M. Ijeomah, G. Okeyoyin, and A. E. Uwatt, "Assessment of human- wildlife conflicts in filing a range of Gashaka Gumti National Park, Nigeria," Polymers for Advanced Technologies, vol. 7, no. 1, pp. 15-35, 2011.

[22] A. Acha and M. Temesgen, "Approaches to human-wildlife conflict management in and around Chebera-Churchura National Park, Southern Ethiopia," Asian Journal of Conservation Biology, vol. 4, no. 2, pp. 136-142, 2015.

[23] M. Dawit, S. .K. Gangwar, H. Bouer, and Y. Tesfay, "Demography, threats and community perception of African elephants (Loxodanta africana) in Kafta-Sheraro National Park, Tigray, Ethiopia," International Journal of Science and Nature, vol. 3, no. 1, pp. 30-36, 2012.

[24] M. E. Tessema, R. J. Lilieholm, Z. T. Ashenafi, and N. LeaderWilliams, "Community attitudes toward wildlife and protected areas in Ethiopia," Society \& Natural Resources, vol. 23, no. 6, pp. 489-506, 2010. 